\title{
Application of Pathway Network Design as Natural Surveillance in Malaysian Public Green Roof
}

\author{
Azlan Ariff Ali Ariff 1, Emma Marine Ahmad Zawawi 1, \\ Julitta Yunus ${ }^{1}$, Rodger Edwards ${ }^{2}$ \\ 1 Faculty of Architecture, Planning, and Surveying, \\ Universiti Teknologi MARA, Malaysia \\ 2 Faculty of Science and Engineering, \\ The University of Manchester, United Kingdom
}

azlanariff@uitm.edu.my, emmarinie@yahoo.com, julitta@uitm.edu.my, rodger.edwards@manchester.ac.uk Tel: 019-2552151

\begin{abstract}
High engagement of crowd in public realm creates a natural surveillance strategy. The selection of types of green roof pathway network design influences the rate of public engagement that helps in assuring public safety while enjoying the green roof facility. The application of Space Syntax as a research methodology helps determine the pathway design layout with the highest traffic concentration. Comparison between a similar number of nodes and axial lines revealed that an axial line with more intersecting points offers more opportunities for better public engagement, shown by higher traffic concentration in tandem with natural surveillance strategy on green roofs.

Keywords: green roof; natural surveillance; space syntax; building simulation

eISSN 2514-751X C2021 The Authors. Published for AMER ABRA cE-Bs by e-International Publishing House, Ltd., UK. This is an open access article under the CC BY-NC-ND license (http://creativecommons.org/licenses/by$n c-n d / 4.0 /$ ). Peer-review under responsibility of AMER (Association of Malaysian Environment-Behaviour Researchers), ABRA (Association of Behavioural Researchers on Asians, Africans, Arabians) and cE-Bs (Centre for Environment-Behaviour Studies), Faculty of Architecture, Planning \& Surveying, Universiti Teknologi MARA, Malaysia.

DOI: https:// 10.21834/ajebs.v6i19.389
\end{abstract}




\subsection{Introduction}

As more urban sprawl replacing open green space while demand for recreational spaces grows due to increased awareness of healthy lifestyles, green roofs, which are primarily intended as a green initiative to reduce urban carbon footprints, are gaining more reputation with the potential to double their function as recreational space in city areas. However, the general public often overlooked a green roof due to its location on the rooftop. In multi-level buildings, the poor route and walkway design cause ineffective public navigation to the green roof. As a result, green roofs hidden from public view are not reachable by the public, having a higher risk of becoming a crime-prone area unfit for public usage.

In the context of functioning as a public realm, green roofs without consideration on the sense of welcoming with no intended activities for the public would not garner public engagement. Like the rest of the green building features, a green roof requires high maintenance (Shafique, Kim, \& Rafiq, 2018), where it becomes a liability to a building if it is not put to proper use. However, the utilisation requires a creative approach that allows the public to benefit from the facility in the long run while ensuring durability and minimising maintenance costs. On the other hand, uncontrolled public accessibility would expose the green roofs to the danger of vandalism, which adds to higher maintenance costs to the green roof, an already expensive building feature. With the absence of working surveillance, the rate of crime around the green roof would increase (Batuman \& Erkip, 2019). Dangerous corners and no perceived escape route towards the dead-end would expose the general public to the danger of becoming the victim and gives out an overall perception of a threatening environment on the green roof that criminals can take advantage of (Kenny, 2020) instead of being a public-friendly space for all. Due to this consensus, building management poses strict measures in allowing only authorised personnel to gain access on top of green roof facilities. Thus, it is no surprise that green roofs in Malaysia are restricted from public access.

Despite the proportionate relationship between high accessibility and crime issue, several notable buildings in Singapore such as Marina Barrage has proven that accessible green roof for the public could attract a large number of crowds where the visitors are happy to describe their experience on Marina Barrage green roof is a safe environment for outdoor recreational purpose and popular tourism spot. While a stringent measure of protecting building infrastructure was initially imposed as a response towards Singapore societal problems and substantial uncertainty, the Marina Barrage management team raised a concern on representing a fresh concept that allows public access and is designed to be more open to the public with a creative approach of maintaining both public and building security. Hence, the idea of adopting natural surveillance by improving public accessibility onto the green roof is born. Sharing the same climate and relatively similar demography, such a move has a huge potential to improve public accessibility and safety of Malaysian green roofs.

\subsection{Research Question}


While it is known that pathways in general functions to provide accessibility and facilitate human movement from one point to another point, different pathway designs are different in terms of distance and rate of public engagement as a result of intersecting points (Omar et al., 2016). These intersecting points, better known as nodes in urban planning design, induce focused traffic concentration, which helps create a safe environment (Abd Rahman, Thani, and Roslan, 2017). With the intention of making green roofs accessible to the public, these few strategies of public space design, such as intersecting points and nodes, can be integrated into the green roof by assessing the important means of green roof accessibility. As green roofs are typically vast green turfing on top of a building, it would be challenging to analyse human circulation behaviour. Thus the assessment of the green roof public accessibility can be assessed by analysing the different manner of pathway layout design in terms of intersecting points, position of nodes, the length of the pathway and how these criteria affects the human traffic movement on the green roof. Hence, the pathway design layout becomes the appropriate medium for assessing human traffic concentration.

The scenario leads to a conundrum; how does the number of intersection nodes in a pathway layout design affect the traffic concentration, and which pathway design has the highest traffic engagement in contribution towards natural surveillance strategy of green roof as public space?

\subsection{Research Aim and Objectives}

This research investigates the relationship between the design layout of green roof circulation with high traffic intensity in improving safety and surveillance aspects that would become the criteria of a highly accessible green roof. The research aim is in line with elaborations of the following objectives; to identify the typical green roof pathway design layout with the highest intersection nodes and to determine which green roof design layout has the highest traffic density. The combination of aim and objective becomes the basis for creating a safe green roof environment for the public based on the benefits of high traffic engagement.

\subsection{Literature Review}

\subsection{Green Roof as Public Space}

The idea of turning green roof as public space is widely accepted globally as urban development continue to threaten green space for recreational use in city areas (Kanniah, 2017). Responding to this dilemma, more recent developments such as office buildings and residential apartments incorporate green roofs as communal spaces that include shared facilities and amenities (Ismail et al., 2018). In Malaysia, rooftop plazas and podiums become a platform for common facilities shared by the residents of exclusive residences. However, this approach does not answer the needs of the general public for recreational areas in city areas where only privileged groups can enjoy these private facilities. The position of green roofs a few floors above ground level and hidden from street-level view 
affects public visibility on the green roof and reduces public accessibility. Without public accessibility, the green roof would only be a stagnant liability that serves no purpose and adds to building maintenance costs (Isa et al., 2021). Public's right on the accessibility to green recreational spaces should not be denied, especially in dense urban development areas. Otherwise, this would cause less public appreciation towards the benefits of the green roof facilities. Besides that, the green roofs which restrict public use show less consideration on pathway design with no clear indication of the activities (Yuliani and Setyowati, 2020). This is evident in green roof buildings in Malaysian cities, as shown in Table 1 below, where the layout of the green roof pathway reflects public accessibility onto the green roof.

Table 1: Types of pathway layout with local green roof examples

\begin{tabular}{|l|l|l|l|l|l|l|}
\hline Layout & Grid & Perimeter & Radial & Centralised & Linear & Diagonal \\
\hline $\begin{array}{l}\text { Examples } \\
\text { of Green } \\
\text { Roof }\end{array}$ & $\begin{array}{l}\text { JST N- } \\
\text { Plant }\end{array}$ & $\begin{array}{l}\text { Heriot-Watt } \\
\text { University }\end{array}$ & $\begin{array}{l}\text { Putrajaya } \\
\text { International } \\
\text { Convention } \\
\text { Center (PICC) }\end{array}$ & The Arc & $\begin{array}{l}\text { Ibu Pejabat } \\
\text { PKNS }\end{array}$ & $\begin{array}{l}\text { Stratosphere } \\
\text { @ The Roof }\end{array}$ \\
\hline Location & $\begin{array}{l}\text { Johor } \\
\text { Bahru }\end{array}$ & Putrajaya & Putrajaya & $\begin{array}{l}\text { Putra } \\
\text { Heights }\end{array}$ & Shah Alam & $\begin{array}{l}\text { Bandar } \\
\text { Utama }\end{array}$ \\
\hline $\begin{array}{l}\text { Public } \\
\text { Access }\end{array}$ & No & $\begin{array}{l}\text { Special } \\
\text { Occasion }\end{array}$ & No & Yes & Restricted & Yes \\
\hline
\end{tabular}

Local planners, designers, architects, and operations teams may learn from the examples of Marina Barrage and Gardens by the Bay, two public areas that welcome a large volume of visitors every year have shown that regardless of the security means that is incorporated in the building, there is still a strong belief that certain qualities should be preserved such as unobtrusive as feasible and should complement the overall architectural value and friendly atmosphere that makes an exemplary public attraction. The ability to achieve such fine balances between otherwise competing physical, social and security needs has been among of the steady indicators that have driven Singapore towards the reputation as one of the most liveable and safest cities in the world, either dealing with the security threats or the risk of terrorism from past decades. In respect to allowing green roofs as a functional public space, it is essential to put public safety as the main priority when the green roof is accessible for the public. Part of ensuring public safety is establishing working surveillance to ensure no one is vulnerable to crime, especially women, children, and senior citizens.

\subsection{Natural Surveillance in Public Space}

Places with high pedestrian traffic give a perception of security (Nilsson, 2019) where help is all around whenever a crime occurs, as opposed to places less travelled by the public where surveillance watch is needed. However, deliberate placement of security teams can give the public perception of an unsafe environment, thus creating a sense of discomfort of being watched over that induces a sense of privacy invasion which eventually deter public 
engagement. Alternatively, adopting natural surveillance, such as strategic entrance points, streetlights, focused and unobstructed views, helps to create a sense of safety in the environment (Mohit and Elsawahli, 2017). The clever positioning of streetlights which allows facial recognition in public spaces, enhances the safety aspect of the environment (Kim and Park, 2017). Formally known as natural surveillance, this high public engagement strategy theoretically provides indirect crime watch monitoring in public space (Othman, Yusoff \& Salleh, 2019) and is one of the approaches in defensible space strategy of Crime Prevention through Environmental Design (CPTED). Natural surveillance is also an arrangement of built environment design features associated with people and activities by benefitting from full surveillance potential. The best defence against crime is to foster a sense of belonging and community by developing cohesion and showcasing the awareness of community, not monitors and keeping the surrounding area under constant watch. This strategy is precedented in The Bridges Centre, Sunderland, where high visibility along the wide, open linear street and throughout the street of Clarence Mew, Hackney creates indirect monitoring from various points of public visibility, thus establishing effective natural surveillance. In Malaysia, the application of the natural surveillance principle is well demonstrated in Bulatan Aman Jaya, Ipoh, as shown in Figure 1, where the location of public space at the centre of busy roundabout creates a pivotal focused view that is highly visible to public that gives a perception of safe environment. A continuous presence of people and surveillance in public spaces occupied by uses and activities that operate until late at night ensures a continuous crowd presence, thus providing natural surveillance. Due to this successful implementation of natural surveillance and secured public safety, Bulatan Amanjaya is open for 24 hours. The availability of a wide array of recreational activities that takes place eliminates the stereotype of associating nighttime with danger behind the dark.

Another aspect of natural surveillance in Crime Prevention through Environmental Design (CPTED) is to create overlapping traffic that promotes traffic engagement. The concentration of people at the overlapping pathway such as junctions crisscross and prominent public space components such as landmarks and plaza creates a node. In an urban contextual study, nodes are perceived as the critical focal point that draws people attention, creating concentrated human traffic and improve the overall perception of a safe environment in public space (Conzens and Sun, 2019). Having pathways where people cross the street creates the eyes on the street where people can look at other people and monitor and react to any event in front of them. This creates a perceived safe environment, as Nilsson (2019) mentioned, where criminals would be less likely to aim at crowded places, putting themselves at risk of being caught by the public, thus deterring the chances of crime. While a shady environment threatens public safety, natural surveillance, on the other hand, puts criminals into vulnerable positions where they could be charged by the public, who stand together to save the victim whenever a crime occurs. This safety assurance would allow the general public, especially families with kids and senior citizens, to confidently engage in the public space and use the facilities provided, thus contributing positively towards a successful public-friendly space. 


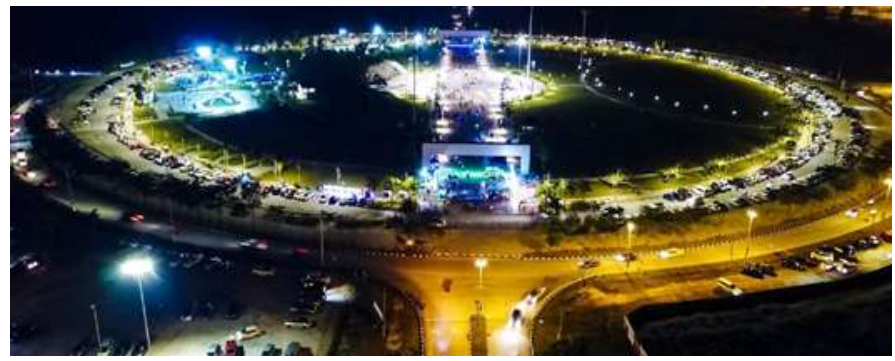

Figure 1: Aerial view of Bulatan Amanjaya in Ipoh, Perak.

(Source: Google Maps)

\subsection{Application of Pathway Design in Natural Surveillance Strategy of Green Roof}

Pedestrian pathway design should prioritise users' experience such as safety, comfort, and continuity (Nasution and Zahrah, 2017). Pathway design with shorter distances increases public mobility to walk with ease, relax, and safely (Omar et al., 2016). Unlike ground-level public spaces, the accessibility of green roofs is primarily determined by public mobility criteria, and the consideration of pedestrian grade system comes second due to less possibility of having overlapping pedestrian circulations with vehicular access. Otherwise, as opposed to creating a safe environment, the idea of integrating a pedestrian grade system onto a green roof would affect public safety with the risk of collision, which does not comply with the intention of keeping public safety in check that eventually deters public interest from actually engaging in the public space. As the green roof pathway is an extension of the building's circulation, the same consideration of public mobility should comply to ensure public inclusivity for a highly accessible green roof as a public space that provides seamless continuity when connected to main pedestrian circulation. This is where the design pathway plays a vital role in allowing more public engagement. Public engagement depends on the connectivity of the path, where a path with more intersections creates more traffic concentration (Nordin and Nakamura, 2019). With relation to the green roof as a public space, some human traffic engaging strategies of public space can be applied onto green roof such as overlapping pathways, clear view and focused circulation around a purposed facility. This public space intervention onto the green roof becomes a node that garners high traffic concentration. A high concentration of traffic establishes active natural surveillance.

\subsection{Application of Space Syntax in Natural Surveillance Strategy of Green Roof} While it is known that pathways in general functions to provide accessibility and facilitate human movement from one point to another point, different pathway designs are different in terms of distance and rate of public engagement as a result of intersecting points (Omar et al., 2016). These intersecting points, better known as nodes in urban planning design, induce a focused concentration of traffic, which helps to create a safe environment (Abd Rahman, Thani, and Roslan, 2017). A selection of theories and strategies for examining the social and cognitive features of an architectural or urban plan in mathematical and 
computational terms is known as Space Syntax. Space Syntax is a popular tool in assessing traffic volume pedestrians in urban studies, which involves spatial analysis of wider scale networks by conducting a series of simulations known as graph analysis. A network in spatial interaction works to identify a series of intersecting points known as nodes and arcs in between segments that are measured by some assumed distance measurement. Nodes or arcs in the network are not counted as unique definitions in any specific means, as spatial interaction works in a neutral setting (Batty, 2017). Sets of segments with respective attributes generate the sequences of links that define streets. Space syntax recognises defined streets by the existence (1) or not (0) of a node in the original network that determines the connectivity of the streets. The definition of a street in an urban study is proportionate to a pathway network in a smaller context, such as the green roof. This definition is applicable in assessing the connectivity of pathways of a green roof that consider the placement of nodes with high traffic concentration to establish natural surveillance on the green roof.

\subsection{Methodology}

The selection of primary pathway layout types for this analysis is based on close reference to local green roof examples documented in Table 1 of the Literature Review chapter to reflect the actual study on the existing green roof scenario. Green roof layout is selected based on typical green roof pathway design layout and controlled at consistent acreage for each variant. Variations of pathway design are endless, where the combination between two or more types of primary pathway layout results in the formation of thousands of possible layouts. Hence, the study focuses on the primary pathway layout and their properties of engaging human traffic. The application of Space Syntax in this study helps to determine which layout has the highest traffic engagement. The conversion of analytic data via simulation into a visual presentation is comprehensive, where different intensity translates into colouration intensity with means of colour-coded maps. As shown in Figure 2 , the red colouration of main road networks indicates high spatial accessibility and the blue colour in tertiary road networks indicate low spatial accessibility.

This presentation provides a more straightforward overview without analysing raw data in the form of elaborated tables and calculations. Detailed data computation is also readily available for in-depth spatial analysis as the computed inputs are generated in the background along with the visual graph analysis. This method of Spatial Design Network Analysis (sDNA) is relevant to the scale of a green roof and applicable to the twodimensional spatial analysis of this study. Space Syntax analysis is later mapped into primal graphs, which translate the samples in a comprehensive illustration where nodes represent intersecting points while edges define pathways. Comparison and relationship between graph analysis obtained from Space Syntax and representation of primal graph would provide a better understanding of how the number of nodes and their positioning contributes to human traffic engagement. Based on the human traffic engagement, the type of pathway 
design layout that suits natural surveillance strategy in the green roof as safe public space can be determined.
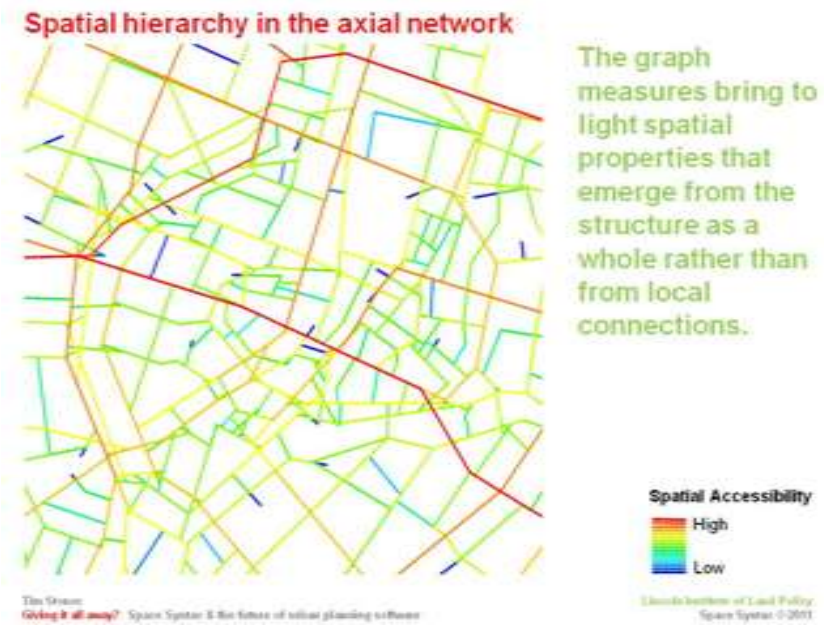

Figure 2: Example of Space Syntax analysis

(Source: https://timstonor.wordpress.com)

\subsection{Results}

Figure 3, Figure 4 and Figure 5 show the conversion of pathway design layout from base pathway layout to axial line to graph analysis as the result of Space Syntax simulation. Generation of axial lines follow the pattern of the pathway layout but is limited to two conditions that allow simulation graph to take place where each axial line must be in a continuous straight line and overlap at the ends to create a connection between two or more axial lines aligned in different orientation and direction. The axial lines are analysed using Depthmapx Space Syntax, thus showing the colour-coded line mapping that provides information on traffic intensity in the form of graph analysis (Figure 5). Graph analysis generated from Space Syntax simulation translated into colour-coded maps shows ranges of colouration from red to indicate high traffic concentration to blue, suggesting low traffic density.
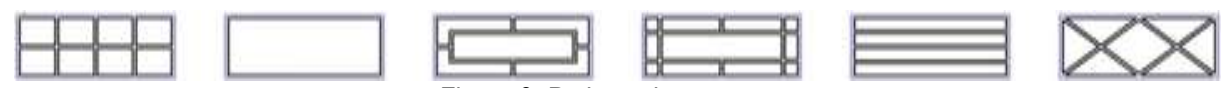

Figure 3: Pathway layout
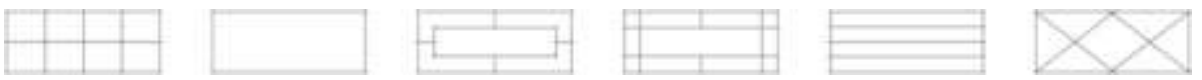
Figure 4: Axial line derived from pathway layout



Figure 5: Graph analysis generated from Space Syntax

Table 2: Types of pathway layout with respective axial lines and nodes count

\begin{tabular}{lllllll}
\hline Layout & Grid & Perimeter & Radial & Centralised & Linear & Diagonal \\
\hline Axial Lines & 8 & 4 & 12 & 10 & 7 & 8 \\
Nodes Count & 15 & 4 & 15 & 20 & 10 & 10 \\
\hline
\end{tabular}

Different pathway layout consists of a different number of axial lines. Configuration of axial lines according to the pattern of pathway layout influences the points of intersection in the pathway design, shown by the nodes count. As shown in Table 2, the radial layout consists of the most number of axial lines, while the centralised layout has the highest nodes count. Despite having the most number of axial lines, the colouration intensity shown in the radial layout is comparatively similar to the perimeter layout, which has only four axial lines. Linear pathway layout shows equal colour intensity with perimeter and radial except for the higher concentration at the middlemost line and the lines connecting both ends. The centralised layout shows more vibrant colour intensity than the grid layout, and the diagonal pathway design exhibits the highest concentration of overall traffic density, as evident by the presence of red-coded axial lines in graph analysis. As an overview, the number of axial lines and the number of nodes is not the dominant factors in determining the rate of traffic engagement. Although both radial layout and centralised layout differ comparatively by a slight difference in terms of the number of axial lines and number of nodes, there is a huge difference in traffic density shown by the deep blue colouration in radial layout, and bright blue colouration suggests stark contrast between the two. The finding extends to another aspect of discussion, which observes the impact of nodes configuration and overlapping axial lines on public engagement.

\subsection{Discussion}

Figure 6 shows the placement of each axial line, while Figure 7 indicates the location of nodes in the respective layout.

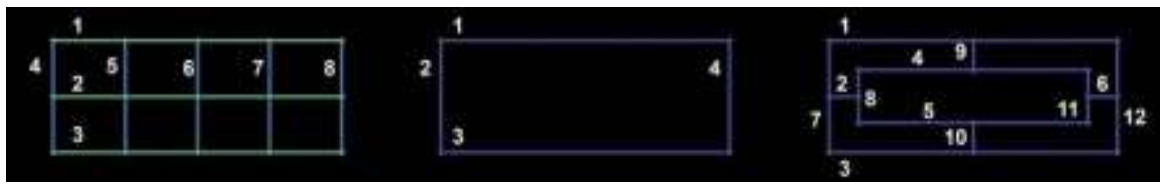

(a)

(b)

(c) 


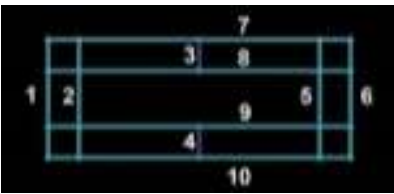

(d)

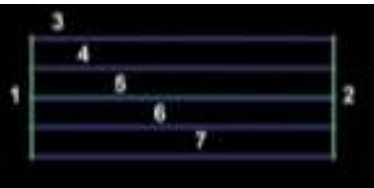

(e)

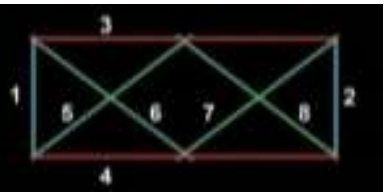

(f)

Figure 6: Axial lines configuration for each pathway layout :

(a) Grid layout; (b) Perimeter layout; (c) Radial layout; (d) Centralised layout; (e) Linear layout; (f) Diagonal layout layout

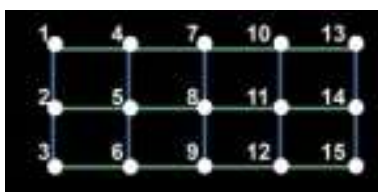

(a)

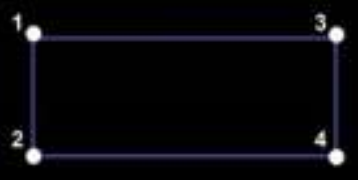

(b)

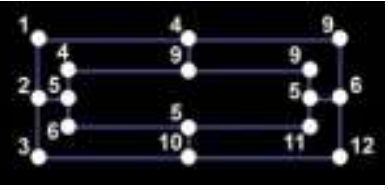

(c)

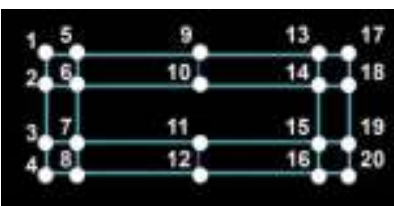

(d)

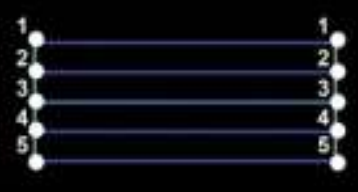

(e)



(f)

Figure 7: Configurations of nodes for each pathway layout:

(a)Grid layout; (b) Perimeter layout; (c) Radial layout; (d) Centralised layout; (e) Linear layout; (f) Diagonal layout

The colour code of the axial line for the perimeter layout shows consistent blue colouration, which suggests an even distribution of low traffic concentration for each axial line. The colouration of radial layout and perimeter layout shows relatively similar intensity, indicating that more axial lines in a pathway design do not significantly improve crowd engagement. However, when comparing the longer axial line with more nodes with the shorter axial line with fewer nodes count, the latter shows higher colouration of crowd density. This suggests that the length of the route has a substantial influence on traffic concentration, supporting the theory that pathway design with shorter distances increases public mobility (Omar et al., 2016). In linear pathway layout, the number of nodes varies by either two or five, where shorter axial lines that connect the perpendicular lines show higher colour intensity than longer axial lines with nodes located at both ends. This further supports that shorter lines with more nodes contribute positively towards high traffic concentration. Compared to linear pathway design, the most extended axial lines in diagonal layout shows the highest traffic intensity compared to other lines. However, both linear pathway design and diagonal pathway design benefits from a similar approach that allows traffic concentration; closely located nodes. 
Table 3: Grid layout nodes count per axial line

\begin{tabular}{lllllllll}
\hline Axial Line & 1 & 2 & 3 & 4 & 5 & 6 & 7 & 8 \\
\hline Intersect Point & 5 & 5 & 3 & 3 & 3 & 3 & 3 & 3 \\
\hline
\end{tabular}

Table 4: Perimeter layout nodes count per axial line

\begin{tabular}{lllll}
\hline Axial Line & 1 & 2 & 3 & 4 \\
\hline Intersect Point & 2 & 2 & 2 & 2 \\
\hline
\end{tabular}

Table 5: Radial layout nodes count per axial line

\begin{tabular}{lcccccccccccc}
\hline Axial Line & 1 & 2 & 3 & 4 & 5 & 6 & 7 & 8 & 9 & 10 & 11 & 12 \\
\hline Intersect Point & 3 & 2 & 3 & 3 & 3 & 2 & 3 & 3 & 2 & 2 & 3 & 3 \\
\hline
\end{tabular}

Table 6: Centralised layout nodes count per axial line

\begin{tabular}{lllllllllll}
\hline Axial Line & 1 & 2 & 3 & 4 & 5 & 6 & 7 & 8 & 9 & 10 \\
\hline Intersect Point & 4 & 3 & 2 & 2 & 3 & 4 & 5 & 5 & 5 & 5 \\
\hline
\end{tabular}

Table 7: Linear layout nodes count per axial line

\begin{tabular}{llllllll}
\hline Axial Line & 1 & 2 & 3 & 4 & 5 & 6 & 7 \\
\hline Intersect Point & 5 & 5 & 2 & 2 & 2 & 2 & 2 \\
\hline
\end{tabular}

Table 8: Diagonal layout nodes count per axial line

\begin{tabular}{lllllllll}
\hline Axial Line & 1 & 2 & 3 & 4 & 5 & 6 & 7 & 8 \\
\hline Intersect Point & 4 & 4 & 6 & 6 & 5 & 5 & 5 & 5 \\
\hline
\end{tabular}

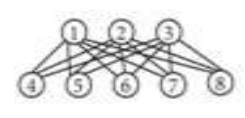

(a)

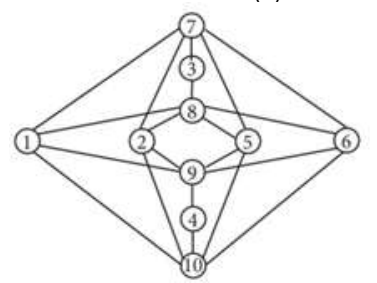

(d)
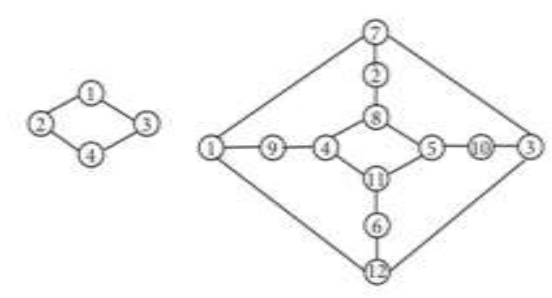

(b)



(e)

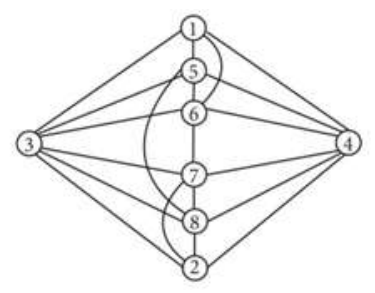

(f)

Figure 8: Primal graph for each pathway layout (a) Grid layout; (b) Perimeter layout; (c) Radial layout; (d) Centralised layout; (e) Linear layout; (f) Diagonal layout

The illustration of the primal graph for each pathway design as shown in Figure 8 above, provides a better understanding of the relationship between nodes, axial lines, and intersecting points. Numbered points are the translation of axial lines where one point could 
become the meeting point of several other points, or one point could connect multiple points. In the Grid layout, only three axial lines intersect with five different lines, and the remaining five axial lines connect to three lines consistently. The perimeter layout in Figure 8(b) shows a constant meeting point of two for each axial line. As for the radial layout shown in Figure 8(c), the number of intersection points for the axial lines ranges between two to three, where points with three intersection points are the axial lines connecting the inner perimeter with the outer perimeter, adhering to the nature of the radial pattern. In the centralised layout shown in Figure 8(d), there is a broader range of nodes count per axial line between two to five. This is because axial lines at the perimeter intersect with internal axial lines that make up the centralised layout pattern. Lastly, the diagonal pathway layout in Figure 8(f) generates more intersection points of four to six per axial line. With the diagonal pathway design, more lines would overlap, creating more nodes located close to each other, as shown in Figure 7(f), which increases the chances of crowd engagement. Concerning natural surveillance, such a layout that garners high traffic concentration within a focused area establishes a safe environment. Thus, by comparing all the variations of the pathway design layout in this study, the best design layout that satisfies the strategy of natural surveillance by creating high traffic concentration is the diagonal pathway layout.

\subsection{Conclusions \& Recommendations}

Pathway layout design plays a vital role in ensuring the public's safety on a green roof to function as a highly accessible public realm. Higher public accessibility introduces more traffic engagement that establishes natural surveillance as part of Crime Prevention through Environmental Design (CPTED) strategy that creates a safe environment onto the green roof for all to enjoy. Through graph analysis generated by Space Syntax, the diagonal pathway design shows the highest traffic intensity as evident in both colour-coded graph analysis, which is indicated by red colouration, and primal graph with a network of overlapping lines and position of nodes suggesting higher chances of crowd concentration. The nature of the diagonal layout satisfies the critical aspects that garner high traffic concentration, namely short distance, more intersecting points, and closeness of nodes that increase the chances of public engagement. This supports the statement by Nordin and Nakamura (2019), thus validates the soundness of Space Syntax as a recommended tool in assessing human traffic behaviour in spatial analysis. Space Syntax as a methodology in determining human interaction within a space helps to simplify the overall computed analysis. Thus, it suits the nature of this study to assess the pathway design layout that has comparative high crowd engagement. Space Syntax eliminates the need to understand elaborated and complicated analytics into graphical translation by adopting colour intensity as visual communication. This study could extend to the assessment of green roof layout using convex space, integration of pedestrian grade system onto the green roof for different types of accessibility, and different variations of layout design which can be formed with a combination of two or more layouts.

\section{Acknowledgement}


Funding towards the presentation and publication of this paper is made possible by REI grant, $600-I R M I / R E I ~ 5 / 3$ (008/2018). The authors fully acknowledged Universiti Teknologi MARA (UiTM) for the approved fund, making this vital research viable and effective.

\section{Article Contribution to Related Field of Study}

This research contributes by extending the study in the current sparse social discourse on the green roof by bridging the relationships between human behaviour and spatial analysis in developing a natural surveillance strategy for highly accessible green roofs. In the Malaysian built environment context, this study would establish the need to make a green roof a green space for the general public to enjoy with no compromise in public safety. The application of natural surveillance on the green roof has a considerable potential to be part of future green roof guidelines in terms of safety measures among the public. In contrast to the popular research instrument in the macro-scale context of urban studies, this article also outlines the soundness of space syntax as the methodology in the micro-scale green roof research.

\section{References}

Ab Rahman, Z., Thani, S. K. S. O., \& Roslan, R. (2017). Demystifying the Roles of Streets towards Improving Urban Quality of Life. Environment-Behaviour Proceedings Journal, 2(5), 427-437.

Batty, M. (2017). Space Syntax and Spatial Interaction: Comparisons, Integrations, Applications.

Batuman, B., \& Erkip, F. (2019). "Night Hawks" Watching Over the City: Redeployment of Night Watchmen and the Politics of Public Space in Turkey. Space and Culture.

Cozens, P., \& Sun, M. Y. (2019). Exploring crime prevention through environmental design (CPTED) and students' fear of crime at an Australian university campus using prospect and refuge theory. Property Management.

Isa, H. M., Sedhu, D. S., Lop, N. S., Rashid, K., Nor, O. M., \& Iffahd, M. (2021). Strategies, Challenges and Solutions Towards The Implementation of Green Campus in UiTM Perak. Planning Malaysia, 19(16).

Kanniah, K. D. (2017). Quantifying green cover change for sustainable urban planning: A case of Kuala Lumpur, Malaysia. Urban Forestry \& Urban Greening, 27, 287-304.

Kenny, J. F. (2020). Lurking in the Shadows: Stranger Danger and Target Selection. In Hiding in Plain Sight (pp. 45-58). Palgrave Macmillan, Cham.

Kim, D., \& Park, S. (2017). Improving community street lighting using CPTED: A case study of three communities in Korea. Sustainable cities and society, 28, 233-241.

Mohit, M. A., \& Elsawahli, H. M. H. (2017). Crime and Housing in Kuala Lumpur: Taman Melati terrace housing. Asian Journal of Environment-Behaviour Studies, 2(2), 53-63.

Nasution, A. D., \& Zahrah, W. (2017). Exploring Ideas in Formulating Urban Design Guidelines for Public Open Space in Sumatra Utara, Indonesia. Environment-Behaviour Proceedings Journal, 2(5), 439-447. 
Nilsson, J. (2019). A Public Space Analysis and Design Proposal for Täby Torg: Understanding Public Life and Designing for It.

Nordin, N., \& Nakamura, H. (2019). The Relation between Objective and Perceived Physical Characteristics of a Neighbourhood Environment for Older People, Environment-Behaviour Proceedings Journal, 4(11), 63-71.

Omar, D., Omar, K. A., Othman, S., \& Yusoff, Z. M. (2016). Walkability design for urban public housing park. Environment-Behaviour Proceedings Journal, 1(3), 311-317.

Othman, F., Yusoff, Z. M., \& Salleh (2019). Identifying Risky Space in Neighbourhood: an Analysis of The Criminogenic Spatio-temporal and Visibility on Layout Design. Environment-Behaviour Proceedings Journal, $4(12), 249-257$.

Shafique, M., Kim, R., \& Rafiq, M. (2018). Green roof benefits, opportunities and challenges-A review. Renewable and Sustainable Energy Reviews, 90, 757-773. 